\title{
Sensitivity of the coupled model of the White Sea dynamics and biochemistry
}

\author{
Ilya Chernov', Alexey Tolstikov², \\ ${ }^{1}$ Institute of Applied Math Research, \\ ${ }^{2}$ Northern Water Problems Institute
}

\begin{abstract}
The JASMINE model based on the prof. N.G. Iakovlev's model of the Arctic Ocean (FEMAO) is the software complex for simulating hydrodynamics and thermal dynamics of a sea; we use the White Sea as an example and also have tried to model other seas. JASMINE allows coupling with special purpose blocks, such as data assimilation or simulation of the sea ecosystem. For that we chose the mature BFM model of pelagic sea biochemistry. An important question is sensitivity of the model with respect to the outer forcing, such as synoptic data (air temperature and pressure, cloud cover, precipitation, wind), boundary values on liquid boundaries, river run-off, initial distributions of the tracers. The White Sea is a convenient model region for such investigation because of dominating tides; thus boundary values become important, while initial distribution is expected not to influence on the results in the long run, at least. The biochemical system also depends on the boundary conditions strongly, and also reacts on the forcing variations. We describe the response of the sea subsystems to different variations of forcing, show what values are crucial and what is not important.
\end{abstract}

Keywords: ecosystem simulation, modelling, thermohydrodynamics, the White Sea.

\section{INTRODUCTION}

Interest to northern seas, especially those of the Arctic region, has been constantly increasing. Numerical and computer simulation, including highperformance computing, become more and more important [1, 2]. However, there is still a lack of models that describe a sea as a complex system, taking into account three-dimensional currents, dynamics of thermohaline fields, sea ice, etc. Existing projects, e.g., NEMO [3], are not all open-source and cannot, usually, be easily adapted for a given sea.

The FEMAO model by prof. N.G. Iakovlev [4], developed for the Arctic Ocean, has been used for simulation of the White Sea [5, 6]. Its sea ice block is very advanced. Ice is described as an ensemble of flakes with thickness distribution. Flakes form a twodimensional continuum.

Using this model as a hydrodynamical core, we develop the software complex JASMINE [7] for simulation of a sea. It has modular structure and can include modules for describing dynamics of ecological system, data assimilation, and other purposes.

\section{THE WHITE SEA}

We use the White Sea as the test sea for verification of the model. The White Sea is rather well studied (see e.g. [8] and references therein) and is important for the Russian Federation. It is convenient for testing numerical models, being semi-closed: it has the single liquid boundary with the Barents Sea. Besides, tidal motion dominates in the sea; this reduces (and almost eliminates) the problem of initial distribution of hydrodynamical fields. Existing data bases concerning the White Sea, open internet resources (e.g., [9]), and new atlases [10] allow comparing model results with both measurements and results obtained by other models. However, the complex can model other seas and oceans: we tried to simulate the Arctic Ocean (geophysical and biochemical fields) and obtained reasonable results.

As for the existing models of the White Sea, we must mention the joint three-dimensional numerical model of hydrodynamics, thermal dynamics, and ecological system of the White Sea developed by I.A.Neelov and O.P. Savchuk [11], operational model by E.V. Semenov [12], and the model by M.V.Luneva [13].

\section{BIOCHEMICAL BLOCK}

The pelagic ecosystem block uses the Italian BFM model [14-15]. It describes interaction and evolution of more than fifty tracers (such as concentrations of nutrients, carbon, nitrogen, phosphorus, etc., in different groups of plankton or bacteria, dissolved matter, etc). Physical model supplies water temperature and salinity, light, and other physical factors; besides, it provides transport of the tracers, their sinking, and describe processes on liquid boundaries and in river mouths. Ecological model is 
able to influence back on the hydrodynamics via water transparency. It is important that three-dimensional transport of a tracer field is time-consuming, so using multiprocessor high-performance hardware is necessary: calculation of ecological dynamics in different grid nodes and transport of different tracers are independent and can be performed in parallel. Acceleration of calculation on computer clusters of Karelian Research Centre [16] and Institute of Numerical Mathematics [17] compared to the modern PC was as high as 300 times. Using this block, we are able to simulate not only physical state of a sea, but also evolution of its ecological system.

The data assimilation block is based on the open source EnKF (Ensemble Kalman Filter) library [18]. Using this technique also demands multiprocessor computers: an ensemble of processes implement the same numerical model with differing factors, using some measurements for correcting the ensemble members.

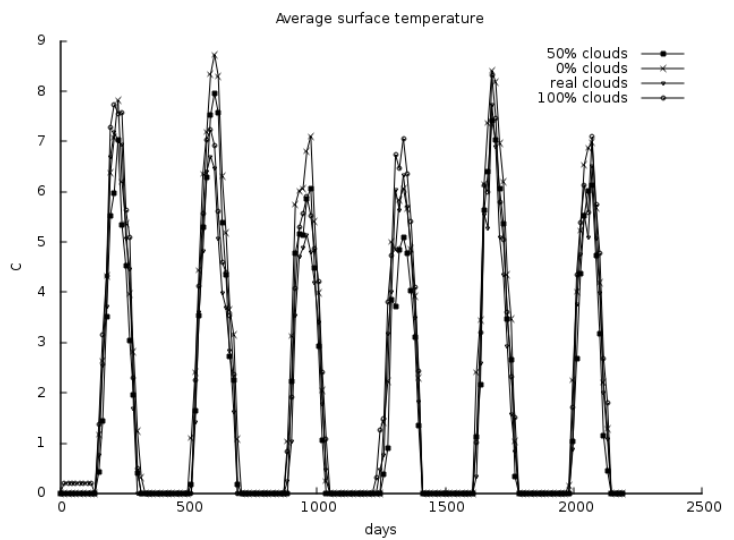

Fig. 1. Average surface temperature of the White Sea depending on clouds, \%

It can be used for restoring missed boundary values using observations (possibly elsewhere), but it demands much computing power.

\section{PROBLEM OF BOUNDARY VALUES}

Boundary values of biochemical and geophysical scalar fields on liquid boundaries and in river mouths are extremely important. Results of modeling depends significantly on the boundary values, so high number of quantities and relatively low amount of data is a serious problem. Simulating the World Ocean to avoid liquid boundaries seems too expensive. However, the developed computer model is able to be adjusted to different seas, so that various seas of the region, including the White Sea, can be simulated at once.

\section{SENSITIVITY PROBLEM}

In context of discussions about global warming, it seems interesting to look how a model sea would react on increase or decrease of global temperature.

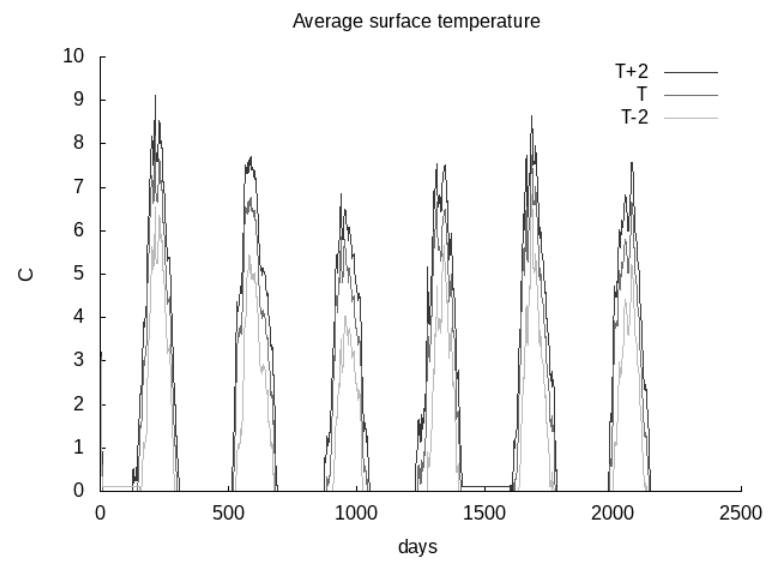

Fig. 2. Average surface temperature (T is water temperature $\left({ }^{\circ} \mathrm{C}\right)$ )

The model forcing includes air temperature and temperature of water at liquid boundaries. We tried to use JASMINE to see reaction of the model of the White Sea on changes of these temperatures. In particular, we compared average water temperature and some biochemical tracers for different scenarios of temperature change in the long run. Given air and boundary temperatures were increased or decreased on $1^{\circ} \mathrm{C}$ or $2^{\circ} \mathrm{C}$.

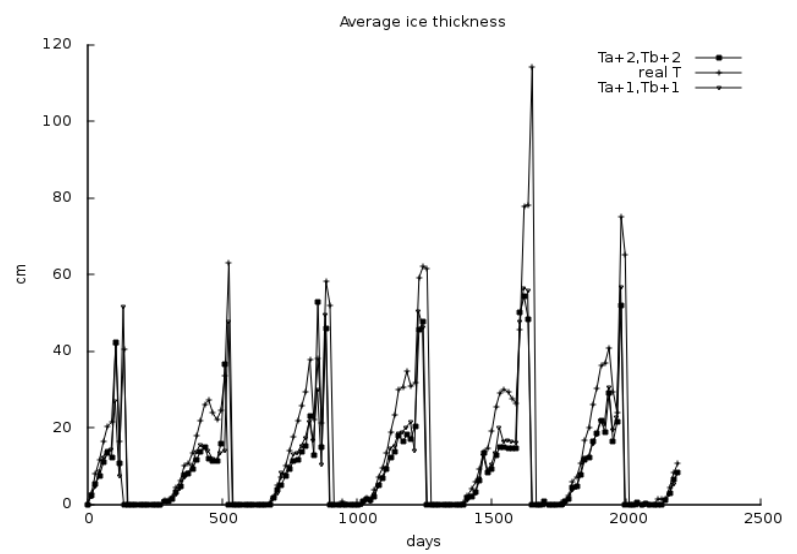

Fig. 3. Average ice thickness (Ta is air temperature $\left({ }^{\circ} \mathrm{C}\right)$, $\mathrm{Tb}$ is boundary temperature $\left({ }^{\circ} \mathrm{C}\right)$ )

Also we changed the cloud cover, comparing real clouds with clear sky, $100 \%$ clouds, and 50\% clouds. Fig. 1 shows how the surface water temperature reacts on the clouds. Note that both clear sky and 100\% clouds produce warmer water compared to the real cloud cover.

As for air and boundary water temperature variations, the general conclusion is that the sea is rather stable with respect to these perturbations: all fields change, though not drastically. Fig. 2 shows surface water temperature for three cases: real conditions, both temperatures $2^{\circ} \mathrm{C}$ higher than real ones, and $2^{\circ} \mathrm{C}$ lower.

Ice thickness reacts strongly on temperature decrease on the liquid boundaries; the reason is that this temperature is (during winter time) low itself, so 
its decrease results in constant ice formation. Fig. 3 and 4 illustrate this: in fig. 3 we see average ice thickness for real conditions, warm air $\left(+2^{\circ} \mathrm{C}\right)$ with water $1^{\circ} \mathrm{C}$ or $2^{\circ} \mathrm{C}$ warmer. Fig. 4 shows only influence of the air temperature: ice thickness hardly changes.

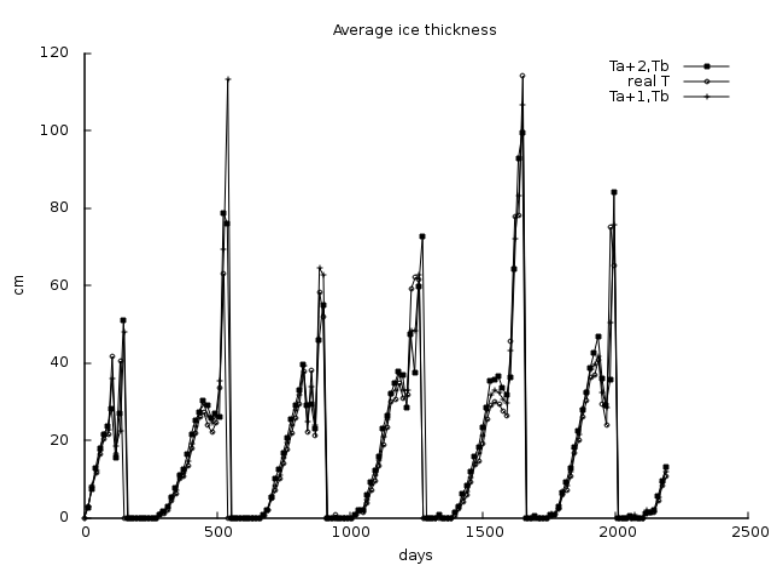

Fig. 4. Average ice thickness (Ta is air temperature $\left({ }^{\circ} \mathrm{C}\right)$; $\mathrm{Tb}$ is boundary temperature $\left({ }^{\circ} \mathrm{C}\right)$ )

As for biochemical tracers, they change even less (see e.g. fig. 5, where oxygen near the surface is compared for the warm, cold, and normal year). The reason is that the highest concentration of plankton organisms is under the surface (5 $\mathrm{m}$ deep or more): there temperature changes are lower.

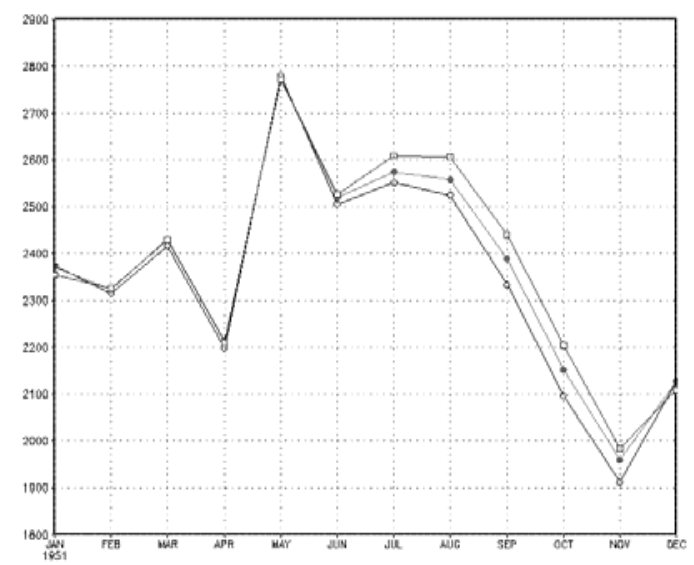

Fig. 5. Average oxygen (respectively downwards: warm, normal, cold year

Preliminary results indicate that distribution of nitrogen, phosphorus, silicon tends to reasonable fields; however, there are still significant problems connected with the lack of nutrient data for simulations on the liquid boundaries.

Also the model sea shows stability with respect to perturbations of the forcing and we believe that this reflects stability of real seas.

\section{REFERENCES}

[1] T. Ringler, M. Petersen, R.L. Higdon, D. Jacobsen, P. W. Jones, M. Maltrud "A multi-resolution approach to global ocean modeling,” Ocean Modelling, vol. 69, pp. 211-232, 2013.

[2] A.S. Sarkisyan, R.A. Ibrayev, N.G. Iakovlev "High resolution and four-dimensional analysis as a prospect for ocean modelling,” Russ. J. Num. Anal. Math. Model., vol. 5(25), pp 477-496, Jan 2010.

[3] NEMO project [Online]. Available: www.nemo-ocean.eu, [Accessed March 20, 2015].

[4] N.G. Iakovlev "On the simulation of temperature and salinity fields in the Arctic Ocean,” Izvestiya, Atmo. Ocean. Phys., Vol.48(1), pp. 86-101, 2012.

[5] I. Chernov, A. Tolstikov "Comparing two models of largescale White sea hydrodynamics and thermal dynamics," in 9th International scientific and practical conference «Environment. Technology. Resources», 20-22 June 2013, Rezekne, Latvia, vol. 1, pp. 13-16.

[6] I. Chernov "Numerical Modelling of Large-Scale Dynamics of the White Sea,” Univ. J. Geosci., vol 1(3), pp. 150-153, 2013.

[7] JASMINE sea modelling project [Online]. Available: https://sites.google.com/site/russianjasmine. [Accessed March 20, 2015].

[8] N. Filatov, D. Pozdnyakov, O.M. Johannessen, L.H. Pettersson, L.P. Bobylev White Sea. Its Marine Environment and Ecosystem Dynamics Influenced by Global Change. Springer-Praxis, 2005.

[9] V.Ja. Berger, A.D. Naumov, N.V. Usov, M.A. Zubaha, I. Smolyar, R. Tatusko, S. Levitus "36-Year Time Series (19631998) of Zooplankton, Temperature and Salinity in the White Sea,' St.-Petersburg, 2003. 362 p. [Online]. Available:www.nodc.noaa.gov/OC5/WH_SEA/WWW/HTML /atlas.html. [Accessed March 20, 2015].

[10] N.N. Filatov, A.V. Tolstikov, M.S. Bogdanova, A.V. Litvinenko, V.V. Menshutkin "Development of an information system and electronic atlas of the status and use of resources of the White Sea and its catchment," Arctic: ecology and economy, vol. 3 (15), pp.18-29, 2013 (in russian).

[11] I.A. Neelov, O.P. Savchuk "3-D IO RAS-AARI Coupled Hydrodinamic-biogeochemical Model of the White Sea," Final report of INCO-Copernicus Project "WHITESEA" No. ICA2-CT-2000-10014: «Sustainable management of the marine ecosystem and living resources of the White Sea»), 2003. 220 p.

[12] E.V. Semenov "Numerical modeling of White sea dynamics and monitoring problem,” Izvestiya, Atmo. Ocean. Phys., vol. 40(1), pp. 114-126, 2004.

[13] N.A. Kasyanova, M.V. Luneva, E.V. Semenov "Effect of hydrophysical processes on the dynamics of chemical biological cycles of the White sea," Izvestiya, Atmo. Ocean.Phys., vol.37(6), pp. 777-786, 2001.

[14] Biochemical Flux Model. [Online]. Available: bfmcommunity.eu, [Accessed March 20, 2015].

[15] M. Vichi, G. Cossarini, M.E. Gutierrez, P. Lazzari, T. Lovato, G. Mattia, S. Masina, W. McKiver, N. Pinardi, C. Solidoro, M. Zavatarelli "The Biogeochemical Flux Model (BFM): Equation Description and User Manual,” BFM Consortium, Bologna, Italy, 2013.

[16] Centre for collective use of the Karelian Research Centre of RAS. [Online]. Available: http://cluster.krc.karelia.ru, [Accessed March 20, 2015].

[17] Institute of Numerical Mathematics of RAS, computer cluster. [Online], Available: http://www.inm.ras.ru/claster, [Accessed March 20, 2015].

[18] Ensemble Kalman Filter. [Online], Available: enkf.nersc.no. [Accessed March 20, 2015]. 